M andel Chu R U B o

\title{
Finanzas para \\ no financieros
}

\section{Quinta edición}

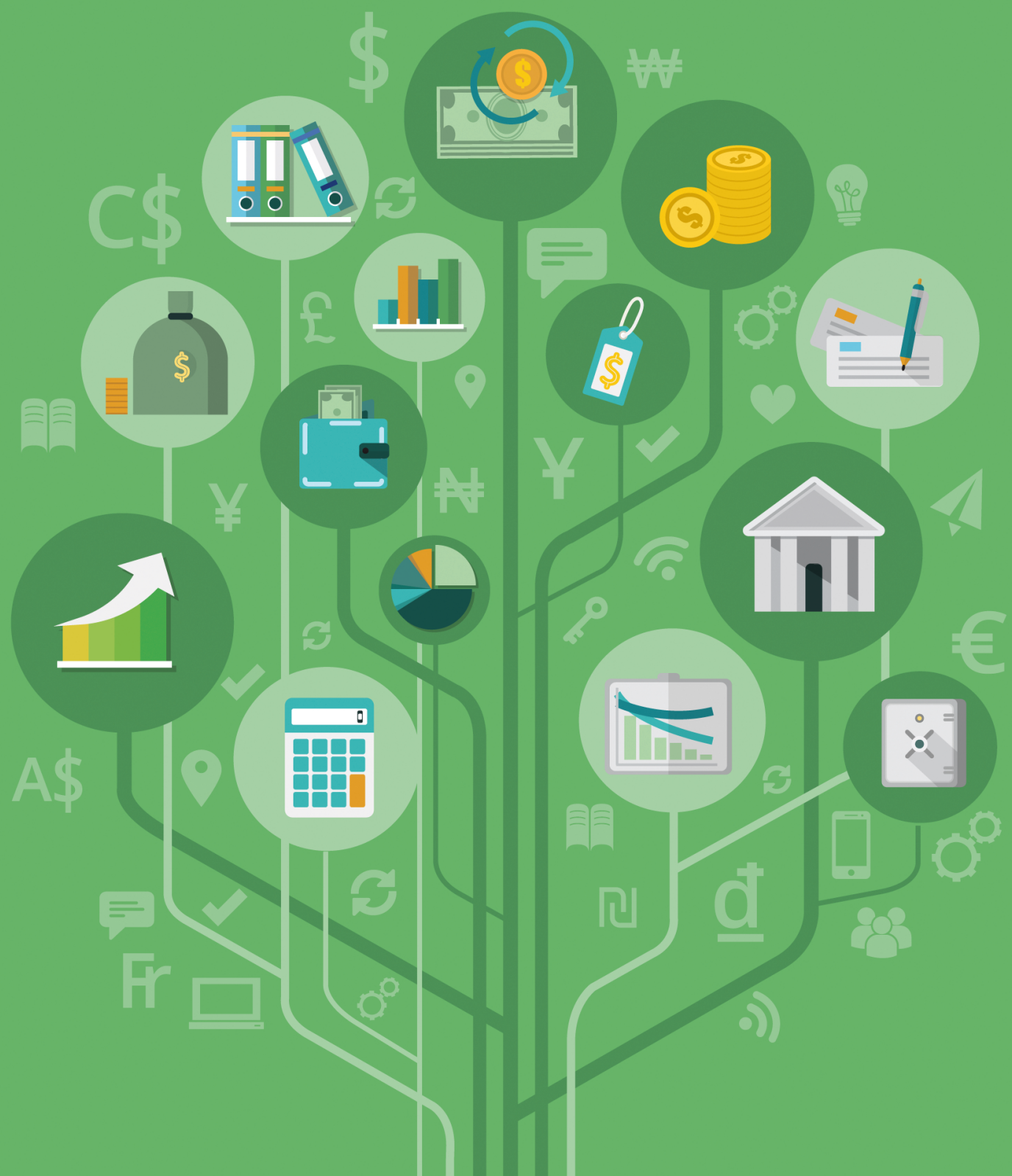




\section{A N U E L H U R U i O}

\section{Finanzas para \\ no financieros}

Quinta edición

Lima, junio de 2016

Universidad Peruana de Ciencias Aplicadas 
(C) Universidad Peruana de Ciencias Aplicadas (UPC)

Primera publicación: mayo de 2007

Impreso en el Perú-Printed in Peru

Edición:

Diana Felix

Corrección de estilo:

Luigi Battistolo

Diseño de cubierta:

Taller LOV S.A.

Diagramación:

Diana Patrón Miñán

Corrección técnica:

Magnolia Ramos

Editor del proyecto editorial

Universidad Peruana de Ciencias Aplicadas S. A. C.

Av. Alonso de Molina 1611, Lima 33 (Perú)

Teléf: 313-3333

www.upc.edu.pe

Primera edición: mayo de 2007

Segunda edición: marzo de 2009

Tercera edición: julio de 2010

Cuarta edición: marzo de 2014

Quinta edición: junio de 2016

Tiraje: 1000 ejemplares

Este libro se terminó de imprimir en el mes de junio de 2016, en los talleres gráficos de imprenta Gráfica Biblos. Jr. Morococha 152, Surquillo - Lima - Perú

\section{Universidad Peruana de Ciencias Aplicadas. Editorial UPC}

\section{Chu Rubio, Manuel}

Finanzas para no financieros / Manuel Chu Rubio.-- Quinta edición.-Lima: Editorial UPC, 2016.

ISBN: 978-612-318-052-2

1. Finanzas 2. Contabilidad financiera 3. Estados financieros 4. Análisis de costos 5. Mercado financiero 6. Dinero 7. Inversiones

332 CHU 2016

Hecho el Depósito Legal en la Biblioteca Nacional del Perú N.²016-07076

Registro de Proyecto Editorial en la Biblioteca Nacional del Perú N. 31501021600550

Todos los derechos reservados. Esta publicación no puede ser reproducida, ni en todo ni en parte, ni registrada en o transmitida por un sistema de recuperación de información, en ninguna forma ni por ningún medio, sea mecánico, fotoquímico, electrónico, magnético, electroóptico, por fotocopia o cualquier otro, sin el permiso previo, por escrito, de la editorial.

El contenido de este libro es responsabilidad del autor y no refleja necesariamente la opinión de los editores. 


\section{Contenido}

Prólogo

$\begin{array}{ll}\text { Introducción } & 11\end{array}$

$\begin{array}{ll}\text { Funciones y responsabilidades de los gerentes } & 13\end{array}$

$\begin{array}{ll}\text { Capítulo 1. Principios de la partida doble } & 17\end{array}$

Capítulo 2. El concepto de las acumulaciones 29

Capítulo 3. El estado de situación financiera y el estado de resultados 45

Capítulo 4. Temas críticos de la contabilidad $\quad 55$

Capítulo 5. Análisis de estados financieros $\quad 61$

Capítulo 6. Conceptos básicos sobre sistemas de costeo 93

Capítulo 7. El sistema financiero 115

$\begin{array}{ll}\text { Capítulo 8. Costo del dinero } & 127\end{array}$

Capítulo 9. Criterios de evaluación de inversiones 221

Capítulo 10. Gerencia basada en valor 243

$\begin{array}{ll}\text { Bibliografía } & 259\end{array}$ 

A Dereck y Kevin, mi inspiración y mi razón de ser 



\section{Prólogo}

Las crisis financieras en Europa, especialmente en Grecia y España, y en Estados Unidos nos han dado una gran lección; jefes, gerentes y directivos, de cualquier empresa, requieren, cada vez más, tener los conocimientos necesarios para el entendimiento de las decisiones financieras básicas. Solo así, todo el cuerpo de ejecutivos de una compañía contribuirá al objetivo de creación de valor para el accionista y, por lo tanto, a la viabilidad de largo plazo de cualquier institución y al éxito económico de los países.

Los responsables del manejo de diversas áreas de cualquier empresa deben necesariamente tomar decisiones en función del objetivo común de creación de valor, para lo cual se necesita, entre otros aspectos, el entendimiento de la relación existente entre el riesgo que cualquier decisión genera y los niveles de rentabilidad esperados.

En la cuarta edición del presente libro, se han actualizado algunos conceptos y reportes financieros, que siguen mostrando de forma didáctica los principios básicos para comprender las decisiones financieras que esencialmente implican riesgo y rentabilidad. Conceptos básicos, como los de costo de oportunidad, valor del dinero en el tiempo y análisis de diversos tópicos contables, se ofrecen aquí, acompañados siempre de ejemplos prácticos relacionados con la gestión financiera.

Además, el libro presenta la estructura de un sistema financiero y posibilita que cualquier sujeto no entendido en la materia, adquiera los conocimientos necesarios para utilizar sus servicios, sea en la búsqueda de alternativas de financiamiento o de inversión, profundizando en aquellas metodologías que permiten determinar el costo del dinero. Hay que destacar el capítulo final del libro, acerca de cómo debe establecerse un sistema gerencial basado en valor.

Por último, deseo felicitar al doctor Manuel Chu Rubio, compañero de aventuras académicas en la Universidad Peruana de Ciencias Aplicadas (UPC), por su constante preocupación de seguir actualizando los conocimientos en el área financiera y por su contribución a la enseñanza de las finanzas, y, por ende, a la mejora en la gestión de las empresas y, consiguientemente, al desarrollo de nuestro país.

Pedro Grados Smith

CEO de Profuturo 



\section{Introducción}

La última crisis internacional, conocida como «crisis de los países desarrollados», nos ha recordado que no somos una isla y que nuestra vida cotidiana está muy ligada al quehacer financiero, lo cual hace imperativo el conocimiento de los conceptos básicos de las finanzas modernas. Los ejecutivos cada vez son más conscientes de que la creación de valor en las empresas se debe dar en el largo plazo.

Entendemos por valor el incremento de las riquezas de los dueños de capital, que no es otra cosa que obtener mayores utilidades e incrementar el valor patrimonial, de tal forma que el valor de la empresa sea cada vez mayor.

¿Cuándo se crea valor? Cuando la rentabilidad obtenida es mayor al costo de capital de los accionistas. Muchos negocios obtienen utilidades e incluso pagan impuestos por utilidades declaradas, pero la pregunta sería si la rentabilidad es mayor a su costo de oportunidad. Si lo anterior no ocurre, no estamos creando valor.

Porque deseamos crear valor, debemos tener en cuenta los siguientes pasos para su implementación:

a. Desarrollar estrategias que nos ayuden a crear valor.

b. Traducir las estrategias en metas de corto y de largo plazo enfocadas en inductores de valor, es decir, en las variables que afecten el valor de la empresa.

c. Introducir sistemas de medición de resultados, así como esquemas de compensación, con la finalidad de motivar e incentivar a los trabajadores para que cumplan las metas establecidas.

Solo podemos crear una filosofía gerencial de valor siempre y cuando contemos con un mínimo conocimiento de finanzas, acompañado de la misión principal de toda empresa: satisfacer las necesidades de sus stakeholders (clientes, proveedores, comunidad, empleados, etcétera). Hay que tomar en cuenta que las ventajas competitivas son producto del valor que toda empresa es capaz de crear para sus stakeholders. 
En esta quinta edición, hemos actualizado los reportes financieros, análisis y ejercicios, con el deseo siempre de introducir, de una forma sencilla y clara, a todos aquellos ejecutivos y profesionales cuya labor diaria no son las finanzas en el mundo de la gestión financiera. Como la obra se dirige a no especialistas, el lenguaje utilizado es muy accesible, de tal forma que no se requiere de una preparación previa en temas financieros.

Manuel Chu Rubio 


\section{Funciones y responsabilidades de los gerentes}

Cuando se indagaba sobre las funciones de los gerentes, no hace mucho tiempo, las respuestas más comunes eran: los gerentes de Ventas son los encargados de proyectar ventas, supervisar el trabajo de ventas, capacitar vendedores, elaborar estadísticas de las ventas, etcétera. Para los gerentes de Producción, las responsabilidades eran adquirir materias primas, diseñar productos, seleccionar maquinaria y equipos, planificar la producción y otras. En cambio, el gerente financiero debía conseguir y aplicar fondos, buscar rentabilidad, distribuir utilidades, etcétera.

Como se observa, todos estaban muy encasillados en tareas específicas. No había una interrelación entre las demás áreas. Para ilustrar mejor esta situación, veamos el siguiente caso:

El gerente de Ventas y Marketing de la fábrica de embutidos La Preferida ha presentado a la gerencia general un proyecto de factibilidad sobre el impulso de la marca El Cerdito. Este proyecto permitirá incrementar las ventas en 20 por ciento al año. En la ejecución del plan estratégico de marketing, la empresa deberá invertir 238.500 dólares (casi siempre es fácil obtener el monto del gasto).

Después de revisar el proyecto, el gerente general consideró que era muy atractivo, pero no suficiente para decidir si podría realizarse, es decir, para saber cuál es el costo-beneficio. Por este motivo, solicitó al gerente de Ventas y Marketing que le respondiera: ¿cuáles son los flujos de caja neto que generará esta nueva inversión?, ¿mejorarán los indicadores financieros?, ¿cuál es la rentabilidad sobre el capital invertido (ROIC) del proyecto?, ¿cuáles son los resultados de los indicadores financieros ROE, ROA?, ¿cuál es el costo de oportunidad de esta nueva inversión?, ¿el proyecto crea valor o no?

Por falta de conocimiento mínimo de finanzas, el gerente de Ventas y Marketing se siente limitado en responder a estas preguntas. Por lo tanto, no puede sustentar la viabilidad de su proyecto, lo cual demuestra que quien no cuenta con un conocimiento mínimo de finanzas no podrá ejercer bien sus funciones en un mundo cambiante que mide el éxito o fracaso de su toma de decisiones a través del desempeño financiero del proyecto. 


\section{¿QUÉ SE ENTIENDE POR FINANZAS?}

Lo primero que se nos viene a la mente es ganar dinero. Pero ¿qué pasa con la liquidez, con la posibilidad de perder y, sobre todo, con el crecimiento autosostenido en el tiempo? Cuando se busca definir qué son las finanzas, hay que tomar en cuenta el equilibrio que debe existir entre las variables: el riesgo, la rentabilidad, la liquidez y la creación de valor. Riesgo, porque existe la posibilidad de perder, incertidumbre generada por el riesgo propio del negocio y por el riesgo del mercado que no es controlable. Rentabilidad, porque hay posibilidad de generar beneficios, reinversión y crecimiento. Liquidez, porque hay la capacidad de cumplir con nuestras obligaciones de corto plazo. Creación de valor, porque existe crecimiento autosostenido en el tiempo.

Cuando se habla de rentabilidad, debemos tener presentes tres conceptos importantes: el costo de oportunidad, el valor del dinero en el tiempo y el análisis de los estados financieros.

\section{EL COSTO DE OPORTUNIDAD}

Recibir dinero hoy no es igual que recibirlo dentro de un año. Esto no solo se debe por la inflación. El prestar un dinero hoy implica dejar de hacer otras cosas con ese dinero, y ese «sacrificio» debe ser compensado, pues estamos dejando de lado alguna «oportunidad».

¿Cuál es el «sacrificio» que estamos haciendo por no invertir esos fondos hoy? Este «sacrificio» puede ser un precio o costo que pagamos o el «costo» en que incurrimos por invertir en una opción en vez de otra. Esto es el costo de oportunidad.

Entonces, el costo de oportunidad es el rendimiento que alguien deja de percibir por ocuparse en una actividad diferente. El costo de oportunidad del dinero es el interés.

\section{EL VALOR DEL DINERO EN EL TIEMPO}

«Un dólar de hoy vale más que un dólar de mañana» por las siguientes razones:

a. Por producción, por rendimientos que puedo obtener al invertir el dinero hoy. Ejemplo, si cuento con 10 dólares y adquiero una camisa al costo unitario de 10 dólares y luego lo revendo en 12 podría obtener 20 por ciento de utilidad. Si 
alguien desea que le preste 10 dólares, como mínimo me tendría que devolver los 10 dólares más el 20 por ciento que estoy dejando de ganar por prestar el dinero.

b. Por inflación, por la posibilidad de que con los 10 dólares no pueda adquirir la misma cantidad de bienes hoy, por la pérdida del poder adquisitivo de la moneda.

c. Por riesgo, por la probabilidad de no recuperar el dinero invertido.

d. Por preferencia por el consumo, por la oportunidad de privarme del consumo hoy, lo cual tiene un precio y debería ser cuantificado de alguna forma.

\section{EL ANÁLISIS DE LOS ESTADOS FINANCIEROS}

Con frecuencia, a la contabilidad se le conoce como «el lenguaje de los negocios». Muchas personas reconocen que la contabilidad y las finanzas son herramientas primordiales para disminuir los riesgos de los negocios y oportunidades, establecer objetivos, medir resultados y tomar decisiones.

El entender los conceptos básicos de la contabilidad y las finanzas es crítico para el desempeño exitoso de todos los gerentes y hombres de negocios, les gusten estos temas o no.

A través de la presentación de conceptos sencillos, el presente libro busca ayudar a los gerentes cuya especialidad o el trabajo diario no son las finanzas, y que se encuentran siempre ocupados; y ofrecer un conocimiento acerca de los conceptos fundamentales de la contabilidad y las finanzas, así como de las prácticas y limitaciones de estos conceptos en los procesos administrativos.

Para ello, se buscará enfatizar más sobre conceptos y elementos esenciales que en explicaciones de los débitos, los créditos y el libro mayor. La idea es explicar cómo se utilizan los conceptos de finanzas y contabilidad en vez de crear información financiera.

Hay dos principios fundamentales en la teoría y práctica contable: el principio de la partida doble y el concepto de acumulado. 



\section{Capítulo 1. Principios de la partida doble}

Para explicar este principio, se puede ilustrar con un caso de la vida diaria la adquisición de un inmueble para vivienda. Esta situación incluye la elección de la casa a comprar. Finalmente, se necesitará de un financiamiento.

Asumamos que el valor de la vivienda es de 90.000 dólares y que se requiere entregar una cuota inicial de 20.000 dólares. Es decir, implica que hará falta un préstamo hipotecario por 70.000 dólares $^{1}$.

Para conseguir el financiamiento, será necesario que el banco realice una evaluación crediticia acerca de cómo podría pagar las cuotas del préstamo. Es decir, qué tanto valor tiene usted. El proceso utilizado para determinar esta información no es específicamente complejo.

En primer lugar, el funcionario del banco desea conocer con qué bienes usted cuenta y cuánto dinero debe y a quién. Asumamos que la respuesta a esas preguntas son las que se presentan en el siguiente cuadro:

\section{Bienes}

Efectivo

Cuenta corriente $\$ 5.000$

Ahorros

Valores

Fondos mutuos
$\$ 15.000$

0

$\$ 10.000$

$\$ 30.000$

1 Trabajaremos algunos casos en dólares para facilitar el cálculo. 
Ahora, consideremos que obtuvo el préstamo hipotecario y que para cancelar la cuota inicial tuvo que retirar 14.000 dólares de su cuenta de ahorros, así como vender parte de los valores que mantenía en los fondos mutuos por un importe de 6.000 dólares (valor precio de mercado de las cuotas del fondo mutuo al momento de la venta). Por lo tanto, ahora usted cuenta con una situación financiera personal diferente, la cual se muestra así:

\section{Bienes}

Efectivo

Cuenta corriente

Ahorros

Valores $^{2}$

Fondos mutuos ${ }^{3}$

Vivienda

\section{Deudas}

Préstamo personal bancario

$\$ 20.000$

$$
\$ 5.000
$$

$\$ 1.000$

0

$$
\$ \quad 4.000
$$

$\frac{\$ 90.000}{\$ 100.000}$

Préstamo hipotecario

$\frac{\$ 70.000}{\$ 90.000}$

El ejemplo anterior es muy simple y el proceso, muy común. Usted ahora no solo cuenta con un inmueble como vivienda, sino también ha empleado algunos conceptos contables claves. Por ejemplo, uno de los hechos básicos que el banco estuvo interesado en conocer fue qué bienes de valor tenía usted. Esta pregunta se podría formular de la siguiente forma: ¿cuáles son sus activos?

«Activos» es el término contable que se utiliza para describir un bien de valor y se expresa en alguna moneda. Estos términos fueron utilizados en su solicitud de crédito presentada al banco. Incluso si usted fuera bendecido por Dios, con buena salud, simpatía y personalidad dinámica, no importa qué tan valiosos sean esos activos, dado que no son fácilmente medibles en valores monetarios y, por lo tanto, no pueden ser anotados en su solicitud de crédito como activos.

En segundo lugar, se le ha preguntado en la solicitud de crédito cuánto debe y a quién. En términos contables, esas obligaciones son conocidas como «pasivos» o «responsabilidades» y representan una obligación legal de cumplimiento. El estar legalmente obligado es, de hecho, ser responsable. Otra forma de definir a los pasivos es «derecho o reclamo sobre los activos». La persona a quien usted le debe tiene un derecho sobre sus activos hasta el monto del crédito pactado. En otras palabras, por lo que posee, es decir, por su patrimonio.

2 Acciones, cuotas de fondos de inversión, bonos, pagarés, etcétera.

3 Patrimonio integrado por aportes de personas naturales y jurídicas, denominadas partícipes, para que estos sean invertidos en valores de oferta pública. 
En nuestro ejemplo usted cuenta con un préstamo personal y, por lo tanto, el banco tiene derecho sobre sus activos (bienes) hasta ese monto. En este caso y el de los otros, los derechos del acreedor sobre esos activos son una responsabilidad o «pasivo».

Si la responsabilidad o pasivo es de 20.000 dólares (préstamo personal bancario), todavía hay obviamente 30.000 dólares de activos (saldo en cuenta corriente, ahorros y fondos mutuos) que pueden ser demandados. Entonces, la siguiente pregunta lógica es: ¿quiénes tienen derechos sobre ellos? Si no existieran otros acreedores, obviamente usted es el propietario, y a esto se llama «patrimonio».

Vale decir, pueden existir dos tipos de responsabilidades: pasivos, que son los derechos de los acreedores; y el patrimonio, derechos de los dueños (o accionistas).

En términos de activos, pasivos y patrimonio, la información financiera de la solicitud de crédito antes y después de la compra podría mostrarse así:

\section{Antes de la compra del inmueble}

Activos

Efectivo y equivalentes al efectivo

Cuenta corriente

Ahorros

Valores negociables

Total de activos
Pasivos

\$ 5.000 Préstamo personal

$\$ 15.000$

$\$ 10.000$ Patrimonio dueño

$\$ 10.000$

$\overline{\$ 30.000}$ Total de patrimonio y pasivos $\overline{\$ 30.000}$

\section{Después de la compra del inmueble}

Activos

Efectivo y equivalentes al efectivo

Cuenta corriente

Ahorros

Valores negociables

Inmueble

Total de activos
Pasivos

$\begin{array}{lrlr}\$ & 5.000 & \text { Préstamo personal } & \$ 20.000 \\ \$ & 1.000 & & \\ & & \text { Préstamo hipotecario } & \$ 70.000 \\ \$ & 4.000 & \text { Patrimonio } & \$ 10.000 \\ \frac{\$ 90.000}{\mathbf{\$ 1 0 0 . 0 0 0}} & \text { Total de patrimonio y pasivos } & \\ \end{array}$

Si observamos los dos estados comparativos, a pesar de que usted cuenta con un inmueble, su patrimonio personal permanece sin cambiar después de la compra. 
La razón, aun cuando sus activos (bienes) se han incrementado, es que también han crecido los derechos de los acreedores sobre esos activos.

Antes se ha explicado que existen dos grupos de demandantes que tienen derechos sobre los activos: acreedores y propietarios. Los acreedores son los primeros que legalmente pueden reclamar esos derechos y el saldo es de los propietarios (patrimonio). Por lo tanto, ni los acreedores ni los propietarios ni ambos juntos pueden tener el derecho de los activos que haya en exceso del total de los activos. Un corolario de este axioma afirma que la suma total de activos tiene siempre que ser igual a la suma total de los pasivos y del patrimonio.

El hecho de que la suma de los activos sea igual a los de los pasivos y del patrimonio es el principio básico de toda la teoría y la práctica contable. Esto es frecuentemente referido a la ecuación básica contable llamada la «partida doble». Los sistemas contables se basan sobre este principio lógico, y todas las transacciones de negocios se registran en términos del efecto de la partida doble sobre los activos, los pasivos y el patrimonio.

El ejemplo anterior envuelve una transacción demasiado simple: la adquisición de un inmueble. Los dos aspectos de esta transacción fueron:

a. Aumento en los activos en un monto de 90.000 dólares, con un incremento similar de pasivos y patrimonio por el mismo monto. Todo registro contable basado en este sistema es conocido como «partida doble».

b. En términos generales, hasta este momento hemos visto tres conceptos básicos: activos, bienes cuyo valor puede ser expresado en una moneda; pasivos, derechos de los acreedores sobre los activos; el patrimonio, que representa los derechos de los propietarios sobre los activos.

Podríamos utilizar esos mismos conceptos y ver cómo se pueden aplicar en una situación de negocios altamente simplificada que incluye a la empresa Mueblería Luis Ibáñez.

Después de trabajar muchos años como representante de ventas en una empresa fabricante de muebles para oficina, Luis Ibáñez decide iniciar su negocio. Para realizarlo, piensa utilizar los ahorros que posee en un banco local por un monto de 15.000 dólares. Si iniciara su negocio el 13 de octubre de 2015, su contabilidad, tomando en cuenta los conceptos anteriores, podría mostrar una hoja de balance de los activos, pasivos y patrimonio así: 


\section{Mueblería Luis Ibáñez \\ Estado de situación financiera de activos y obligaciones \\ al 13 de octubre de 2015}

\begin{tabular}{llll} 
Activos & \multicolumn{2}{c}{ Patrimonio } & \\
Efectivo y equivalentes al efectivo & $\$ 15.000$ & Patrimonio & $\$ 15.000$
\end{tabular}

Si el 30 de noviembre, Luis decide adquirir un camioneta pick up de segundo uso al contado, valorizada en 5.000 dólares, para despachar su mercadería, la contabilidad se mostraría de la siguiente forma:

\section{Mueblería Luis Ibáñez}

Estado de situación financiera de activos y obligaciones

al 30 de noviembre de 2015

Activos

Efectivo y equivalentes al efectivo

Vehículo

Total de activos
Patrimonio

Patrimonio $\$ 15.000$

$\$ 5.000$

$\$ \overline{15.000}$

Total patrimonio $\$ 15.000$

Ahora, asumamos que una semana después solicita un préstamo por 5.000 dólares. Tan pronto lo reciba, su contabilidad se reflejaría así:

\section{Mueblería Luis Ibáñez}

\section{Estado de situación financiera de activos y obligaciones} al 8 de diciembre de 2015

\section{Activos}

Efectivo y equivalentes al efectivo

Vehículo

Total de activos

\section{Patrimonio}

\$15.000 Préstamo bancario

$\$ 5.000$

$\$ 5.000$ Patrimonio

$\$ \overline{20.000}$ Total de patrimonio y pasivos $\$ \overline{20.000}$ 
Supongamos que ha realizado la contabilidad hasta este momento. Aplicando los mismos conceptos que utilizamos en nuestro caso de la compra de la vivienda, el contador ha preparado la situación financiera de Mueblería Luis Ibáñez a través de los estados que se elaboraron antes. Esta evaluación, similar a la solicitud de crédito de nuestro anterior ejemplo, representa el estado de situación financiera de los activos, pasivos y patrimonio del negocio en un momento determinado a esa fecha.

En la contabilidad, a ese reporte se le conoce como estado de situación financiera. Este es uno de los documentos básicos de contabilidad y se utiliza para presentar un informe sobre la situación financiera de una empresa. Se le denomina estado de situación financiera, dado que muestra siempre los valores de los activos, pasivos y patrimonio y el concepto de la partida doble.

En circunstancias normales del negocio, el saldo de los activos, pasivos y patrimonio se debe reportar en un estado de situación financiera en constante cambio. Por ejemplo, cada uno de los estados de situación financiera presentados por la mueblería es diferente de los otros, como resultado de las transacciones que realizó la mueblería de Luis Ibáñez cada uno de esos días. Es decir, el activo caja (efectivo), en casi todas las empresas, puede cambiar varias veces durante un día e incluso en una hora.

Por lo tanto, un estado de situación financiera puede reflejar la situación de los activos, pasivos y patrimonio solo en un momento dado. Por esto, el estado de situación financiera se indica siempre con fechas, que son elementos críticos para entender la información financiera presentada.

Muchas empresas preparan un estado de situación financiera formal al menos una vez al año. Por lo general, a fin de año.

A continuación se muestra un estado de situación financiera de Unión Andina de Cementos S. A. A. (antes Cementos Lima S. A. A.), al 31 de diciembre de 2014 y 2013. 


\section{Union Andina de Cementos S. A. A. Unacem S. A. A. (antes Cementos Lima S. A. A.) \\ Estados financieros - Individual \\ anual al 31 de diciembre de 2014 - 2013 \\ (en miles de soles)}

\section{Activos \\ Activos corrientes}

\section{Cuenta}

Notas

2014

2013

Efectivo y equivalentes al efectivo

Cuentas por cobrar comerciales y otras cuentas por cobrar

$7 \quad 60.951$

196.750

$8 \quad 268.994$

234.857

Cuentas por cobrar comerciales (Neto)

62.965

48.879

Otras cuentas por cobrar (Neto)

Cuentas por cobrar a entidades relacionadas

103.360

105.707

Anticipos

84.137

66.506

18.532

Inventarios

9

602.529

13.765

Otros activos no financieros

8.053

Total activos corrientes

940.527

Activos no corrientes

Otros activos financieros

Inversiones en subsidiarias, negocios conjuntos y asociadas

Cuentas por cobrar comerciales y otras cuentas por cobrar

10

Cuentas por cobrar comerciales

8

3.257 .994

1.645 .786

48.456

29.170

222

344

Otras cuentas por cobrar

45.894

Cuentas por cobrar a entidades relacionadas

Anticipos

2.340

4.680

Propiedades, planta y equipo (Neto)

Activos intangibles distintos de la plusvalia

3.905 .181

68.849

3.706 .550

11

9.745

Otros activos no financieros

135.952

12

426.177

8.366.704

Total activos no corrientes

5.602 .138

Total de activos

6.542 .784 


\section{Union Andina de Cementos S. A. A. - Unacem S. A. A. (antes Cementos Lima S. A. A.) Estados financieros - Individual anual al 31 de diciembre de 2014-2013 \\ (en miles de soles)}

Pasivos y patrimonio
Pasivos corrientes
Otros pasivos financieros
Cuentas por pagar comerciales y otras cuentas por pagar
Cuentas por pagar comerciales
Otras cuentas por pagar
Cuentas por pagar a entidades relacionadas
Ingresos diferidos
Otras provisiones
Total pasivos corrientes
Pasivos no corrientes
Otros pasivos financieros
Cuentas por pagar comerciales y otras cuentas por pagar
Cuentas por pagar a entidades relacionadas
Otras provisiones
Pasivos por impuestos diferidos
Otros pasivos no financieros
Total pasivos no corrientes
Total pasivos
Patrimonio
Capital emitido
Otras reservas de capital
Resultados acumulados
Otras reservas de patrimonio
Total patrimonio
Total pasivo y patrimonio

Notas

2014

2013

15

14

573.293

332.553

93.135

76.166

64.527

98.725

20.671

926.517

3.313 .373

9.714

9.714

13.492

472.536

6.940

31,1 (i)

3.816.055

4.742 .572

19
693.406

219.080

121.109

43.052

44.987

9.932

15.814

928.300

1.627 .954

11.883

11.883

13.663

537.303

5.557

2.196.360

3.124 .660

1.646.503

270.203

1.503 .096

(1.678)

3.418.124

6.542 .784 
Como se aprecia, en el estado de situación financiera de Unacem es muy importante la fecha, la cual indica exactamente la situación del estado de los activos, pasivos y patrimonio de la empresa. Si vemos en la parte inicial del estado de situación financiera, se muestra una lista de los activos que posee la empresa (Algunas cuentas del estado de situación financiera de Unacem pueden resultar poco familiares para usted. En este punto, se puede ignorar el hecho, dado que estamos mirando el estado de situación financiera en términos conceptuales mucho más amplios, que se presentarán con detalles más adelante).

En la segunda página (pasivo y patrimonio) se observan los derechos u obligaciones de los activos, es decir, partidas contables que nos dicen quiénes son los que tienen derechos sobre los activos.

Tenemos a los pasivos corrientes (obligaciones de corto plazo) ${ }^{4}$, pasivos no corrientes (obligaciones de largo plazo) ${ }^{5}$ y el patrimonio.

El tamaño y la complejidad de los activos, pasivos y patrimonio de una empresa pueden variar, pero los conceptos básicos que deben estar presentes en la elaboración de un estado de situación financiera permanecen intactos. Estos conceptos son aplicables a las pequeñas y grandes empresas. Ellos se aplican también a los procesos contables de todo tipo de negocios, ya sea en entidades comerciales y de manufactura o en aquellas organizaciones que combinan ambas actividades. Estos conceptos incluso se aplican al creciente sector de empresas que ofrecen servicios, como la empresa de servicios de energía eléctrica, Luz del Sur S. A. A.

4 Menor a 360 días.

5 Mayor a 360 días. 
Luz del Sur S. A. A.

Estado de situación financiera al 31 de diciembre de 2014-2013

(en miles de soles)

Cuenta
Activos
Activos corrientes
Efectivo y equivalentes al efectivo
Cuentas por cobrar comerciales y otras cuentas por cobrar
Cuentas por cobrar comerciales (Neto)
Otras cuentas por cobrar (Neto)
Cuentas por cobrar a entidades relacionadas
Inventarios
Otros activos no financieros
Total activos corrientes
Activos no corrientes
Otros activos financieros
Inversiones en subsidiarias, negocios conjuntos y asociadas
Cuentas por cobrar comerciales y otras cuentas por cobrar
Otras cuentas por cobrar
Propiedades de inversión
Propiedades, planta y equipo (Neto)
Activos intangibles distintos de la plusvalia
Total activos no corrientes
Total de activos

Notas

2014

2013

Activos

Activos corrientes

Efectivo y equivalentes al efectivo

$7 \quad 12.858$

9.157

387.037

351.312

$8 \quad 369.390$

337.299

$9 \quad 14.832$

11.577

$10 \quad 2.815$

2.436

$11 \quad 26.792$

21.353

7.288

6.277

433.975

388.099

12

163.301

115.562

57.886

16.960

$9 \quad 57.886$

16.960

$13 \quad 21.776$

20.370

14

3.177 .583

2.908 .453

507

468

$3.421 .053 \quad 3.061 .813$

$3.855 .028 \quad 3.449 .912$ 
Luz del Sur S. A. A.

Estado de situación financiera al 31 de diciembre de 2014-2013 (en miles de soles)

Pasivos y patrimonio
Pasivos corrientes
Otros pasivos financieros
Cuentas por pagar comerciales y otras cuentas por pagar
Cuentas por pagar comerciales
Otras cuentas por pagar
Cuentas por pagar a entidades relacionadas
Otras provisiones
Pasivos por impuestos a las ganancias
Total pasivos corrientes
Pasivos no corrientes
Otros pasivos financieros
Cuentas por pagar comerciales y otras cuentas por pagar
Otras cuentas por pagar
Otras provisiones
Pasivos por impuestos diferidos
Total pasivos no corrientes
Total pasivos
Patrimonio
Capital emitido
Otras reservas de capital
Resultados acumulados
Otras reservas de patrimonio
Total patrimonio
Total pasivo y patrimonio

\begin{tabular}{rrr} 
Notas & \multicolumn{1}{l}{$\mathbf{2 0 1 4}$} & \multicolumn{1}{l}{$\mathbf{2 0 1 3}$} \\
& & \\
15 & 183.875 & 300.342 \\
& 341.860 & 294.464 \\
16 & 213.663 & 184.166 \\
$17-18$ & 128.193 & 110.233 \\
10 & 4 & 65 \\
19 & 11.077 & 8.223 \\
27 & 13.403 & 5.550 \\
& $\mathbf{5 5 0 . 2 1 5}$ & $\mathbf{6 0 8 . 5 7 9}$ \\
& & \\
15 & 1.186 .090 & 857.310 \\
& 31.324 & 35.050 \\
17 & 31.324 & 35.050 \\
19 & 1.934 & 1.645 \\
28 & 289.020 & 338.968 \\
& $\mathbf{1 . 5 0 8 . 3 6 8}$ & $\mathbf{1 . 2 3 2 . 9 7 3}$ \\
& $\mathbf{2 . 0 5 8 . 5 8 3}$ & $\mathbf{1 . 8 4 1 . 5 5 2}$ \\
& & \\
20 & 331.127 & 331.127 \\
20 & 143.321 & 143.321 \\
20 & 831.380 & 691.060 \\
20 & 490.617 & 442.852 \\
& $\mathbf{1 . 7 9 6 . 4 4 5}$ & $\mathbf{1 . 6 0 8 . 3 6 0}$ \\
& $\mathbf{3 . 8 5 5 . 0 2 8}$ & $\mathbf{3 . 4 4 9 . 9 1 2}$
\end{tabular}


En todos los casos, la información contable tiene usuarios internos y externos. Los primeros son los gerentes y personas que toman decisiones que necesitan responder a las preguntas: ¿cuánto efectivo se requiere para enfrentar las necesidades operativas y cumplir con los acreedores a corto plazo?, ¿cuál debe ser el costo y la rentabilidad de los productos y servicios?, ¿dónde y cuánto de los recursos se debe asignar?

Hay dos tipos de usuarios externos: aquellos con interés directo, quienes son afectados por los resultados contables, como los acreedores e inversionistas, y los interesados indirectamente en el desempeño de la empresa, como las agencias de recaudación de impuestos, los analistas financieros, los competidores, los inversionistas en bolsa de valores y los potenciales inversionistas. 
Para poder revisar todo el contenido de esta edición, visite nuestra tienda virtual.

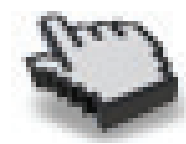

ManUEL. CHU RUBio

\section{Finanzas para}

\section{no financieros}

Quinta edición

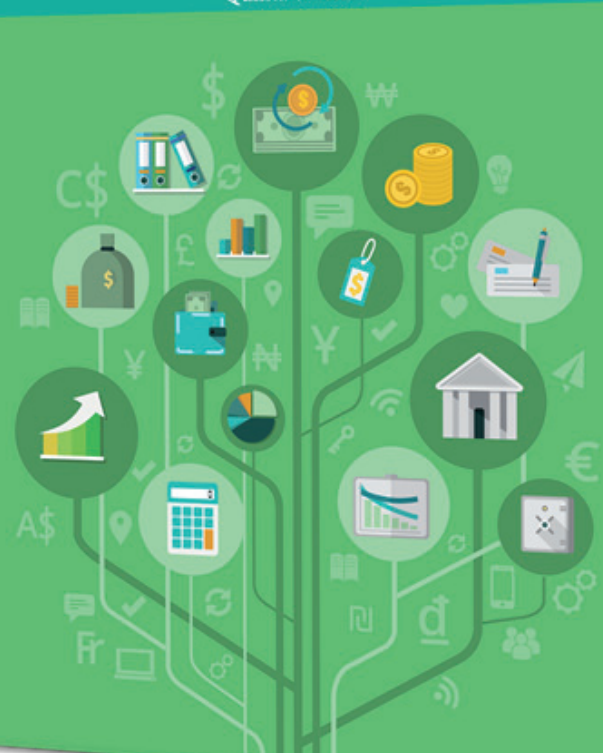

